\title{
Delay in diagnosis: malaria in a returning traveller
}

\author{
Andrea K. Boggild MD MSc, Andrea V. Page MD, Jay S. Keystone MD MSc (CTM), \\ Andrew M. Morris MD SM(Epi), W. Conrad Liles MD PhD
}

$\mathrm{A}$ 68-year-old Canadian woman originally from the Democratic Republic of Congo returned to Canada after a 10-month stay in the Congo where she was visiting friends and relatives. She had taken no chemoprophylaxis for malaria and sought no pretravel advice. Three days after returning to Canada, she began to have fever, nausea and vomiting. She visited a walk-in clinic, but she was sent home with no specific therapy. Later that day, she presented to an emergency department, and she was again discharged home. Four days after the onset of symptoms, she was taken to the emergency department by her family, who found her to be lethargic, confused, feverish and incontinent.

Thick and thin smears for malaria were performed. An infection of Plasmodium falciparum was detected, with 35\% parasitemia (Figure 1). The patient was transferred to our hospital, where she was admitted to the intensive care unit. She was given quinine intravenously and 1 cycle of exchange transfusion. Although she had hypoglycemia (glucose in random samples $3.1 \mathrm{mmol} / \mathrm{L}$ ), hyperbilirubinemia (total bilirubin 78 $\mu \mathrm{mol} / \mathrm{L}$ ), mild acute renal failure (creatinine $119 \mu \mathrm{mol} / \mathrm{L}$ ) and thrombocytopenia (platelet count $16 \times 10^{9}$ cells/L), her symptoms responded well to quinine and a solution of $10 \%$ dextrose in water. Within 24 hours, she was coherent and afebrile.

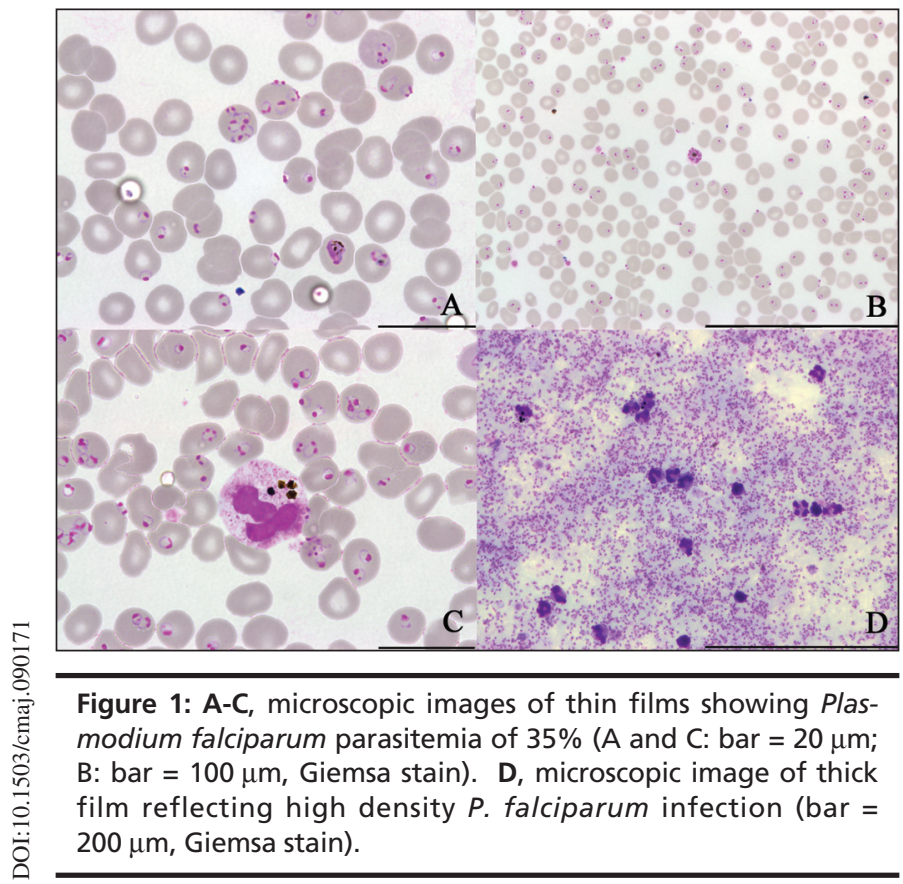

\section{Key points}

- Malaria should be considered and excluded for any traveller with fever returning from an area where malaria is endemic, regardless of their country of birth.

- People travelling to visit friends and relatives are less likely than other travellers to seek pretravel advice or to take chemoprophylaxis, and they are more likely to travel to rural areas for prolonged periods.

- Malaria caused by Plasmodium falciparum can quickly progress to severe complications and death, especially in those who are not immune.

- Early diagnosis and prompt treatment are essential for successful outcomes.

Repeat malaria smears performed 12,24 , and 48 hours after admission revealed parasitemia of $9.5 \%, 3 \%$ and $<1 \%$, respectively. Intravenous quinine therapy was stopped and her treatment course was completed with quinine and doxycycline taken orally for 7 days total. She was discharged after 3 days in hospital. At this time, she had normoglycemia (glucose in random samples $4.2 \mathrm{mmol} / \mathrm{L}$ ), mild anemia (hemoglobin $103 \mathrm{~g} / \mathrm{L}$ ) and thrombocytopenia (platelet count $76 \times 10^{9}$ cells/L). There was no parasitemia at discharge, and she was well 6 months after discharge.

\section{Discussion}

Malaria is a potentially fatal, but readily treatable, condition. This case highlights the importance of obtaining a travel history for febrile patients and including malaria in the differential diagnosis for those who have recently travelled to regions where malaria is endemic. Fever is a common manifestation of travel-acquired illness and occurs in about one-quarter of returning travellers who visit post-travel clinics. ${ }^{1,2}$

\section{Clinical presentation}

Malaria is caused by protozoan parasite members of the genus Plasmodium and is transmitted via bites from infected Anopheles mosquitoes. Almost all deaths due to severe malaria are caused by infection with P. falciparum (Box 1).

From the Tropical Diseases Unit (Boggild, Keystone) and the Division of In fectious Diseases (Boggild, Page, Keystone, Morris, Conrad, Liles), Toronto General Hospital, University Hospital Network and Mount Sinai Hospital; and the Department of Medicine (Page, Keystone, Morris, Conrad, Liles), University of Toronto, Toronto, Ont. 
Box 1: Criteria for diagnosing severe Plasmodium falciparum malaria ${ }^{16}$

Detection of asexual forms of $P$. falciparum on a bloodsmear or a compatible history

AND

One or more of the following:

- Severe normocytic anemia (hemoglobin < $50 \mathrm{~g} / \mathrm{L}$ )

- Impaired consciousness or unrousable from a coma with a score less than 10 on the Glasgow Coma Scale

- Shock with systolic blood pressure $<80 \mathrm{~mm} \mathrm{Hg}$

- Prostration with extreme weakness

- Acute renal failure with a urine output $<400 \mathrm{~mL}$ in 24 hours and serum creatinine $>265 \mu \mathrm{mol} / \mathrm{L}$

- Pulmonary edema or acute respiratory distress syndrome

- Hypoglycemia (plasma glucose $<2.2 \mathrm{mmol} / \mathrm{L}$ )

- Spontaneous bleeding or disseminated intravascular coagulation

- Repeated generalized convulsions (> 2 within 24 hours)

- Acidemia or acidosis (arterial $\mathrm{pH}<7.25$, plasma bicarbonates $<15 \mathrm{mmol} / \mathrm{L}$ or venous lactate $>15 \mathrm{mmol} / \mathrm{L}$ )

- Macroscopic hemoglobinuria not associated with oxidant drugs and RBC enzyme defects

- Jaundice detected clinically or total serum bilirubin $>50 \mu \mathrm{mol} / \mathrm{L}$

- Parasitemia of $>5 \%$ in people who are not immune to $P$. falciparum infection

Adapted from Boggild AK and Kain KC. Malaria: clinical features, management, and prevention. In: Heggenhougen HK, Quah S, editors. International encyclopedia of public health. Vol.5. p. 371-382. Copyright Elsevier Science (2008).

Fever is a common chief complaint of patients with malaria and occurs in $80 \%-90 \%$ of cases. ${ }^{3-6}$ Other symptoms, such as malaise, coughing, vomiting, diarrhea, abdominal pain or headache, may be predominant. More than $90 \%$ of patients with malaria caused by $P$. falciparum show symptoms within 1 month of returning from travel. Almost all present for care within 2 months of the initial infection, although this may be delayed if the patient has taken chemoprophylaxis. ${ }^{1,6,7}$

Malaria is endemic throughout the tropics and subtropics. The prevalence of malaria is high in sub-Saharan Africa and parts of Oceania, where the relative risks of malaria among travellers are 207.6 and 76.7, respectively. ${ }^{7}$ Malaria can be prevented by a combination of mosquito-avoidance measures (e.g., mosquito netting, insect repellents, coils and sprays) and chemoprophylactic agents. No chemoprophylactic agent is $100 \%$ effective; thus, malaria should still be considered in febrile patients who have taken prophylaxis. Obtaining a detailed travel history, including destination, nature and duration of travel and adherence to preventive measures, in addition to a clinical history, is essential for diagnosing malaria.

About 400 cases of malaria occur each year in travellers returning to Canada. Most of these cases are caused by infection with $P$. falciparum, which can quickly lead to severe and potentially fatal disease in people who are not immune, including tourists, business travellers and people visiting friends and relatives. Although many people who grew up in countries where malaria is endemic believe themselves to be immune, ${ }^{7.8}$ immunity begins to wane within 6 months of departure from the endemic area in the absence of re-exposure..$^{9-11}$ Thus, malaria should be included in the differential diagnosis of fever for people who were born in or previously lived in areas where malaria is endemic.

\section{Malaria in children}

Children born in countries where malaria is not endemic who travel to areas with malaria (e.g., their parents' place of birth) represent a particularly vulnerable group of travellers. In this group of children, reported adherence to appropriate chemoprophylaxis is only $3 \%-15 \%$. This may be, in part, attributed to the false assumption on the part of parents that their children are protected because of their ethnic background. ${ }^{12,13}$ In many European countries, the greatest number of imported cases of malaria are among children. ${ }^{12}$ Peak incidences of imported malaria in children visiting friends and relatives coincide with school holidays, mainly during the summer months and December and January. ${ }^{12}$

Children are more likely than adults to present with nonspecific symptoms, such as fever, lethargy and malaise, and gastrointestinal complaints, such as nausea, vomiting, abdominal pain and diarrhea. They are also more likely to have hepatosplenomegaly and jaundice. Children, especially those under 5 years of age, are more vulnerable to severe and cerebral manifestations of malaria. ${ }^{4,6,12}$

\section{Making the diagnosis}

Of the imported cases of $P$. falciparum malaria in Canada, about 15 per year will have severe manifestations, leading to 1-2 deaths annually. ${ }^{6}$ Inadequate or no chemoprophylaxis, the inability of health care providers to recognize the importance of fever in returned travellers, and the delayed initiation of treatment all contribute to the burden of severe imported malaria in Canada. ${ }^{6,14}$ Exclusion of malaria requires 3 separate blood smears performed and promptly read at 12 -hour intervals over a $24-48$ hour period. ${ }^{5,6}$ If a dipstick assay is used, it must be followed up with confirmatory blood smears, which allow for quantification of parasitemia and a determination of the species.

In this case, the patient made a complete recovery, despite having greater than $30 \%$ parasitemia and systemic involvement; this is an atypical result. A recent case series described 7 cases of fatal imported malaria in Canadian travellers or visitors to Canada. ${ }^{14}$ None of these patients had the level of parasitemia observed in our patient. Although prompt initiation of parenteral antimalarial therapy can be life-saving for those with severe malaria, the fatality rate in this group remains between $10 \%$ and $30 \%$, even if patients receive appropriate therapy. ${ }^{4,6}$ Thus, recognition of malaria as a potential cause of illness in returned travellers, coupled with early diagnosis and initiation of treatment before the development of severe manifestations, provides the greatest likelihood of a successful clinical outcome. Uncomplicated malaria is easily treated with short courses of antimalarial drugs taken orally. Most patients who receive quick diagnosis and treatment re- 
cover uneventfully. Physicians should strongly consider seeking support from a consultant or an expert in infectious diseases for any patient in whom the diagnosis of malaria is confirmed (Box 2).

Malaria continues to pose a diagnostic dilemma for physicians in countries where it is not endemic. ${ }^{5,14,15}$ This case is a reminder to all front-line clinicians to suspect malaria in re-

\section{Box 2: Malaria and travel-related resources for health care providers \\ Travel \\ Public Health Agency of Canada \\ - www.phac-aspc.gc.ca/tmp-pmv/index-eng.php \\ Committee to Advise on Tropical Medicine and Travel \\ - www.phac-aspc.gc.ca/publicat/ccdr-rmtc/06pdf /acs-32-06.pdf \\ Centers for Disease Control and Prevention \\ - wwwn.cdc.gov/travel/contentYellowBook.aspx \\ - wwwn.cdc.gov/travel/ \\ World Health Organization \\ - www.who.int/ith/en/index.html}

United Kingdom's National Travel Health Network and Centre

- www.nathnac.org/travel/index.htm

International Society of Travel Medicine

- www.istm.org

\section{Malaria}

World Health Organization

- www.who.int/topics/malaria/en/

- www.who.int/malaria/wmr2008/

Centers for Disease Control and Prevention

- www.cdc.gov/malaria/

\section{Prevention and treatment}

Public Health Agency of Canada

- www.phac-aspc.gc.ca/publicat/ccdr-rmtc/04vol30/30s1 /index-eng.php

World Health Organization

- www.who.int/malaria/docs/TreatmentGuidelines2006.pdf Centers for Disease Control and Prevention

- www.cdc.gov/malaria/diagnosis_treatment/tx_clinicians.htm

- www.cdc.gov/malaria/control_prevention/index.htm

\section{Surveillance and outbreak information}

Canada Communicable Disease Report

- www.phac-aspc.gc.ca/publicat/ccdr-rmtc/index-eng.php

Morbidity and Mortality Weekly Report

- www.cdc.gov/mmwrl

WHO Weekly Epidemiological Record

- www.who.int/wer/en/index.html

ProMedmail

- www.promedmail.org/pls/otn/f?p=2400:1000: turning travellers who present with fever and to obtain a travel history, particularly if the patient's primary complaint is fever.

This article has been peer reviewed.

Competing interests: None declared.

\section{REFERENCES}

1. Wilson ME, Weld LH, Boggild A, et al. Fever in returned travelers: results from the GeoSentinel Surveillance Network. Clin Infect Dis 2007;44:1560-8.

2. Freedman DO, Weld LH, Kozarsky PE, et al. Spectrum of disease and relation to place of exposure among ill returned travelers. N Engl J Med 2006;354:119-30.

3. Boggild AK, Yohanna S, Keystone JS, et al. Prospective analysis of parasitic infections in Canadian travelers and immigrants. J Travel Med 2006;13:138-44.

4. Boggild AK, Kain KC. Malaria: clinical features, management, and prevention. In: Heggenhougen HK, Quah S, editors. International encyclopedia of public health. Vol. 5. San Diego (CA): Academic Press; 2008. p. 371-82.

5. Newman RD, Parise ME, Barber AM, et al. Malaria-related deaths among US travelers, 1963-2001. Ann Intern Med 2004;141:547-55.

6. Suh KN, Kain KC, Keystone JS. Malaria. CMAJ 2004;170:1693-702.

7. Freedman DO. Malaria prevention in short-term travelers. $N$ Engl J Med 2008;359:603-12.

8. Leder K, Tong S, Weld L, et al. Illness in travelers visiting friends and relatives: a review of the GeoSentinel Surveillance Network. Clin Infect Dis 2006;43:1185-93.

9. Colbourne MJ. Malaria in Gold Coast students on their return from the United Kingdom. Trans R Soc Trop Med Hyg 1955;49:483-7.

10. Taylor TE, Strickland GT. Malaria. In: Strickland GT, editor. Tropical medicine and emerging infectious diseases. 8th ed. Philadelphia (PA): WB Saunders; 2000. p. 614-43.

11. Mascarello M, Allegranzi B, Angheben A, et al. Imported malaria in adults and children: epidemiological and clinical characteristics of 380 consecutive cases observed in Verona, Italy. J Travel Med 2008;15:229-36

12. Ladhani S, Aibara RJ, Riordan FAI, et al. Imported malaria in children: a review of clinical studies. Lancet Infect Dis 2007;7:349-57.

13. Bradley D, Warhurst D, Blaze M, et al. Malaria imported into the United Kingdom in 1992 and 1993. Commun Dis Rep CDR Rev 1994;4:R169-72.

14. Kain KC, MacPherson DW, Kelton T, et al. Malaria deaths in visitors to Canada and in Canadian travellers: a case series. CMAJ 2001;164:654-9.

15. Mali S, Steele S, Slutsker L, et al. Malaria surveillance - United States, 2006. MMWR Surveill Summ 2008;57:24-39.

16. World Health Organization. Severe falciparum malaria. Trans $R$ Soc Trop Med Hyg 2000;94(Suppl 1):1-90

Correspondence to: Dr. Andrea K. Boggild, Tropical Diseases Unit, Toronto General Hospital, 200 Elizabeth St., North Wing, 13th Floor, Rm. 1350, Toronto ON M5G 2C4; fax 416 340-3260; andrea.boggild@utoronto.ca

The section Cases presents brief case reports that convey clear, practical lessons. Preference is given to common presentations of important rare conditions, and important unusual presentations of common problems. Articles start with a case presentation (500 words maximum) and a discussion of the underlying condition follows (1000 words maximum). Generally, up to 5 references are permitted and visual elements (e.g., tables of the differential diagnosis, clinical features or diagnostic approach) are encouraged. Written consent from patients for publication of their story is a necessity and should accompany submissions. See information for authors at www.cmaj.ca. 